\title{
MicroRNA-143-5p targeting eEF2 gene mediates intervertebral disc degeneration through the AMPK signaling pathway
}

\author{
Qi Yang ${ }^{1 \dagger}$, Xiao-Peng Guo ${ }^{1 \dagger}$, Yan-Li Cheng ${ }^{2}$ and Yang Wang ${ }^{3 *}$
}

\begin{abstract}
Background: Intervertebral disc degeneration (IDD) is a major contributor to back, neck, and radicular pain, and the treatment of IDD is costly and relatively ineffective. Dysregulation of microRNAs (miRNAs) has been reported to be involved in IDD. The purpose of our study is to illustrate the potential that miR-143-5p targeting eEF2 gene mediates IDD.

Methods: Following the establishment of the IDD rat models, expression of miR-143-5p, eEF2, Bcl-2, Bax, AMPK, mTOR, cyclinD, COL2, ACAN, and DCN was detected. The NP cells isolated from degenerative intervertebral disc (IVD) were introduced with a series of mimic, inhibitor, or AICAR to explore the functional role of miR-143-5p in IDD and to characterize the relationship between miR-143-5p and eEF2. Cell viability, cell cycle, apoptosis, and senescence were also evaluated.

Results: A reduction in eEF2, an increase in miR-143-5p, and activation of the AMPK signaling pathway were observed in degenerative IVD. Moreover, increased senescent NP cells were observed in degenerative IVD. eEF2 was confirmed as a target gene of miR-143-5p. miR-143-5p was found to activate the AMPK signaling pathway. The restoration of miR143-5p or the activation of AMPK signaling pathway decreased COL2, ACAN, and DCN expression, coupled with the inhibition of NP cell proliferation and differentiation, and promotion of NP apoptosis and senescence. On the contrary, the inhibition of miR-143-5p led to the reversed results.
\end{abstract}

Conclusion: The results demonstrated that the inhibition of miR-143-5p may act as a suppressor for the progression of IDD.

Keywords: MicroRNA-143-5p, EEF2, AMPK signaling pathway, Nucleus pulposus cells, Differentiation, Apoptosis, Senescence

\section{Background}

Intervertebral disc degeneration (IDD) is a common complex disease of the spine, leading to musculoskeletal disability and poor quality of life for patients $[1,2]$. IDD is often accompanied with low back pain (LBP), radiculopathy, or myelopathy, and its lifetime incidence rate is greater than $90 \%$ [3]. Prominent changes occur during IDD, including loss of extracellular matrix, altered phenotype of normal disc cells, and the release of pro-inflammatory cytokines [4]. It is interesting to note that nucleus pulposus (NP) was responsible for maintenance of

\footnotetext{
* Correspondence: Dryyywang@163.com

${ }^{\dagger} \mathrm{Qi}$ Yang and Xiao-Peng Guo contributed equally to this work.

${ }^{3}$ The 2nd Ward of Department of Neurosurgery, Taihe Hospital, No. 32,

Renmin South Road, Maojian District, Shiyan 442000, Hubei Province,

People's Republic of China

Full list of author information is available at the end of the article
}

disc function and structure [5]. The accelerated apoptosis and senescence of NP cells were found to be a possible cause for IDD [6]. Protection against NP cell apoptosis and senescence may be conducive for the amelioration of IDD $[7,8]$. A previously conducted study demonstrated that reinsertion of activated NP cells can delay the process of disc degeneration [9]. This prompted us to improve understanding of the biology of the intervertebral disc (IVD) healing and to identify strategies to enhance the regenerative process. In previous investigations, microRNAs (miRNAs) were reported for their deregulation in NP cells, with effect on the proliferation and apoptosis of NP cells, or their relationship with breakdown of balance between (ECM) synthesis and degradation in NP cells in IDD [10-12]. 
MiRNAs can downregulate the gene expression by targeting mRNAs for translational repression and/or cleavage, which enables them critical roles in cellular processes such as proliferation, invasion, apoptosis, and senescence [13]. A previous study has confirmed that miR-143-5p plays a significant role in epithelial-mesenchymal transition (EMT) and metastasis of gallbladder cancer [14]. Besides, it has also been proven to involve in the progression and prognosis of cervical cancer [15]. Furthermore, recent evidence has revealed that miR-143 is upregulated in degenerative disc tissues [16]. A study conducted by $\mathrm{Mu}$ et al. found that miR-143 affects proliferation and apoptosis of human hypertrophic scar fibroblasts (HSFs) and inhibits ECM production-associated protein through suppression of the Akt/mTOR pathway [17]. As was previously reported, eukaryotic elongation factor 2 (eEF2) is a target of mTOR [18], and thus it was speculated that miR-143 could modulate eEF2. Furthermore, eEF2 has been predicted to be a target of miR-143-5p by using the online prediction program. The eEF2 gene has been proven to be a common calcium/calmodulin $(\mathrm{Ca} / \mathrm{CaM})$-dependent Ser/Thr-kinase that is activated by mitotic agents involved in cell proliferation and apoptosis [19]. eEF2 kinase (eEF2K), an enzyme that inactivates eEF2, is activated by AMP-kinase (AMPK) and contributes to cell survival $[20,21]$. Tumor cells exploit this pathway to adapt to nutrient deprivation via reactivating the AMPK-eEF2K signaling pathway [22]. Recently, Wang et al. have provided evidence showing that resveratrol has the ability to promote NP cell autophagy via activation of AMPK signaling pathway, thus acting as a novel preventive role in IDD [23]. Based on the aforementioned literature, a hypothesis can be drawn that miR-143-5p is involved in IDD via the AMPK signaling pathway by regulating eEF2. In this present study, the functions of miR-143-5p on NP cells of IDD rats were explored, as was the underlying mechanism involving the AMPK signaling pathway.

\section{Methods}

\section{Ethics statement}

This study was carried out in strict accordance with the recommendations in the Guide for the Care and Use of Laboratory Animals. All efforts were made to minimize suffering of the animals. The experimental procedures were approved by the Animal Ethics Committee of Taihe Hospital.

\section{Study subjects}

Fifteen male Lewis rats, weighing 297 to $323 \mathrm{~g}$ and aged 12 to 14 weeks, were purchased from the Laboratory Animal Research Center of Southern Medical University (Guangzhou, China). A week before treatment, the rats were housed with free access to water and food, under a 12-h light/dark cycle with the environment at $22 \sim 24{ }^{\circ} \mathrm{C}$ with the humidity of $50 \sim 60 \%$.

\section{Establishment of IDD model}

IDD models were developed as previously reported [24]. In brief, 15 male Lewis rats aged 12 14 weeks were selected for the experiments. Rat coccygeal vertebrae (Co6/Co7 and Co7/Co8) were punctured using the $18-\mathrm{G}$ needle, in order to establish the model of IDD. Besides, the rats $(\mathrm{Co} 8 / \mathrm{Co} 9)$ without puncture were regarded as the control group. The central NP (nucleus pulposus), $5 \mathrm{~mm}$ distant from the skin, was the object of puncture. The pinpoint was rotated for $360^{\circ}$ and kept for $30 \mathrm{~s}$. Images of X-ray and magnetic resonance imaging (MRI) were obtained of every rat coccygeal vertebra before the puncture and in the second week and the fourth week after the puncture. The disc height index (DHI) (\%) and rate of disc height change (RDHC) were calculated [24]. The degeneration degree of caudal IVD of rats was graded as follows: I was normal, II was slight IDD, III was moderate, and IV was serious [25], and the rate of IDD was calculated as previously described [26]. All IDD grades and imaging analysis were conducted by three independent surgeons, twice respectively so as to evaluate the reliability of the rating system. The rats with typical IDD, which was confirmed through imaging, were all euthanatized by $\mathrm{CO}_{2}$ inhalation 4 weeks later. IDD specimen, obtained after dissecting the rats, was used for hematoxylin-eosin (HE) staining and immunohistochemistry.

\section{HE staining}

Parts of degenerative IVD tissues (Co6/Co7 or $\mathrm{Co} 7 / \mathrm{Co} 8)$ and normal IVD tissues (Co8/Co9) were extracted for the HE staining. The target IVD tissues (Co7-Co8 and Co8-Co9) and adjacent caudal vertebrae were excised, then fixed with $3 \%$ neutral formaldehyde, embedded with paraffin, and cut into 5- $\mu \mathrm{m}$-thick sections. Following the cutting period, the tissue sections were dewaxed with xylene twice (each time for $5 \mathrm{~min}$ ), then rehydrated with $100 \%, 95 \%, 80 \%$, and $75 \%$ gradient ethanol respectively for $1 \mathrm{~min}$ and rinsed for $2 \mathrm{~min}$ under running water. Sections were then stained with hematoxylin for $2 \mathrm{~min}$ and rinsed with running water for $10 \mathrm{~s}$, followed by color separation with $1 \%$ hydrochloric acid ethanol for $10 \mathrm{~s}$. Then sections were then rinsed by distilled water for $1 \mathrm{~min}$ and stained with eosin for $1 \mathrm{~min}$. Following the eosin staining periods, sections were dehydrated by $95 \%$ and $100 \%$ ethanol for two times (each time $1 \mathrm{~min}$ ) after being washed by distilled water for $10 \mathrm{~s}$. Finally, sections were permeabilized by xylene and then mounted by neutral balsam. 


\section{Safranin 0 staining}

The tissues were fixed with $4 \%$ paraformaldehyde, dehydrated, permeabilized, and then paraffin embedded. The paraffin-embedded tissues were sliced into 5 - $\mu \mathrm{m}$-thick sections. After this, the tissue sections were dewaxed and stained conventionally using hematoxylin and eosin. Following that, the sections were stained with $0.5 \%$ Safranin $O$ for $5 \mathrm{~min}$. After washing under distilled water, the tissue sections were dehydrated twice using $95 \%$ and $100 \%$ gradient ethanol ( 2 min each time). After that, the sections were permeabilized using xylene and sealed with neutral balsam.

\section{Immunohistochemistry}

Degenerative IVD and normal IVD tissues were respectively fixed with $10 \%$ formalin, embedded into paraffin, and cut into $4-\mu \mathrm{m}$ sections. The tissue sections were then baked at $60^{\circ} \mathrm{C}$ for $20 \mathrm{~min}$; dewaxed with xylene I, xylene II, and xylene III (10 min for each); immersed in absolute ethanol I, absolute ethanol II, and $90 \%$ waterethanol ( 2 min for each); treated with $3 \% \mathrm{H}_{2} \mathrm{O}_{2}$ for 15 min; and then washed by distilled water three times (each time for $2 \mathrm{~min}$ ). The tissue sections then underwent microwave antigen retrieval. Following the antigen revival period, the sections were immersed in the $0.01 \mathrm{M}$ citrate buffer solution ( $\mathrm{pH}$ 6.0) and heated in a microwave oven until boiling. After $5 \mathrm{~min}$, sections were further heated until boiling. After another 5-min period, sections were cooled down to room temperature. Then, the sections were blocked with $10 \%$ bovine serum albumin at $37^{\circ} \mathrm{C}$ for $30 \mathrm{~min}$. After the surplus serum was discarded, primary antibody to eEF2 (1:2000, ab75748, Abcam, Cambridge, MA, USA) was added into sections until they were completely covered, and incubated at $4^{\circ}$ $\mathrm{C}$ overnight. After that, sections were incubated at $37^{\circ} \mathrm{C}$ for $1 \mathrm{~h}$ and then washed by $0.02 \mathrm{M}$ phosphate buffered saline (PBS) three times (each time for $5 \mathrm{~min}$ ). After being washed via PBS, sections were added with secondary antibody and goat anti-rabbit immunoglobulin G (IgG) (DF7852, Shanghai Yao Yun Biotechnology Co., Ltd., Shanghai, China) for incubation at $37^{\circ} \mathrm{C}$ for $30 \mathrm{~min}$, and washed with $0.02 \mathrm{M}$ PBS three times (each time for $5 \mathrm{~min}$ ). Sections were added with a horseradish peroxidase-labeled streptomycin avidin reagent, incubated at $37^{\circ} \mathrm{C}$ for $30 \mathrm{~min}$, and then washed with 0.02 PBS three times (each time for $5 \mathrm{~min}$ ). Following that, sections were developed by diaminobenzidine (DAB) under conditions void of light, which was controlled under the microscope for $5 \mathrm{~min}$, and then fully washed by distilled water. After being washed by distilled water, sections were counterstained with hematoxylin for 1 min, conventionally dehydrated by ethanol and permeabilized, and sealed with neutral gum. The staining was observed under a microscope, with the brownish yellow particles regarded as positive. Five high-power visual fields $(\times 400)$ were randomly chosen from each section with 100 cells counted in each field. The mean values of percentage of positive cells in total cells were then calculated. The experiment was performed three times.

\section{Cell culture}

Following a successful model establishment for 4 weeks, 4 rats were given lethal doses of $\mathrm{CO}_{2}$, with the spine separated to expose normal and IDD spine under an aseptic condition. The fibrous ring was cut with a scalpel to separate gelatinous nucleus, which then was rinsed in sterile D-hanks three times to remove bloodstain. NP tissues were cut into blocks at a size of $1 \times 1 \times 1 \mathrm{~mm}$ and placed into a centrifuge tube. After that, the tube was added with twofold volume of $0.1 \%$ type II collagenase, placed in a water bath at $37^{\circ} \mathrm{C}$ for digestion, and then shaken every $10 \mathrm{~min}$. After the digestion period, the tissues were centrifuged at $179 \times g$ for $5 \mathrm{~min}$ with the supernatant removed, and detached with $10 \mathrm{U} / \mathrm{mL}$ hyaluronidase in a water bath for $2 \mathrm{~h}$. Tissues were centrifuged at $179 \times g$ for $5 \mathrm{~min}$ and then washed by Dulbecco's modified Eagle's medium (DMEM)-F12 three times. Following the counting period, cells were inoculated into $25-\mathrm{cm}$ culture flasks at $1 \times 10^{6}$, added with DMEM-F12 containing $100 \mathrm{U} / \mathrm{mL}$ streptomycin and 15\% fetal bovine serum (FBS), and cultured in a cell incubator with $5 \% \mathrm{CO}_{2}$ at $37^{\circ} \mathrm{C}$. The medium was changed after a week and then changed every 3 days. Following a 20-day period, when the cells were detached from the wall, a fibroblast region with long spindle and polygonshaped cells was scrapped with cell scraper and then suspended in culture medium. Meanwhile, the circular and short shuttle-shaped NP cells were retained under a phase-contrast microscope. Afterwards, the flask was rinsed with culture medium two times and continually cultured. Until the circular and short shuttle-shaped NP cells turned into the clone population with single morphology, the cells were treated with $0.25 \%$ trypsin for resuspension, and then inoculated into another culture flask for further culture.

\section{Cell transfection and grouping}

The abovementioned cultured cells were grouped into control group (NP cells from normal IVD), blank group (NP cells from degenerative IVD without any transfection), negative control (NC) group (NP cells from degenerative IVD transfected with miR-143-5p negative control sequence), miR-143-5p mimic group (NP cells from degenerative IVD transfected with miR-143-5p mimic), miR-143-5p inhibitor group (NP cells from degenerative IVD transfected with miR-143-5p inhibitor), AICAR group (NP cells from degenerative IVD added 
with $0.5 \mathrm{mmol} / \mathrm{L}$ AICAR, AMPK signaling pathway activator), and miR-143-5p inhibitor + AICAR group (NP cells of degenerative IVD added with $0.5 \mathrm{mmol} / \mathrm{L}$ AICAR and transfected with miR-143-5p inhibitor). Twenty-four hours before the transfection, cells were inoculated into a six-well plate. The transfection was conducted based on the instructions of lipofectamine 2000 (11668-019, Invitrogen, Carlsbad, CA, USA) when the cell confluence reached 30 to $50 \%$. The 100 pmol aliquots of miR-143-5p mimic, miR-143-5p inhibitor, miR-143-5p inhibitor + AICAR, and AICAR were all separately diluted with $250 \mu \mathrm{L}$ of serum-free Opti-MEM (51985042, Gibco, Gaitherburg, MD, USA) to the final concentration of $50 \mathrm{nM}$, followed by incubation at room temperature for $20 \mathrm{~min}$. A $5-\mu \mathrm{L}$ aliquot of lipofectamine 2000 was diluted with $250 \mu \mathrm{L}$ serum-free medium, followed by incubation at room temperature for $5 \mathrm{~min}$. The abovementioned two mixtures were mixed completely and allowed to incubate at room temperature for $20 \mathrm{~min}$. Following this, the cells were incubated with the mixture in an incubator with 5\% $\mathrm{CO}_{2}$ at $37^{\circ} \mathrm{C}$ for 6 to $8 \mathrm{~h}$. Then, the medium was changed into the complete medium in order to culture for another 24 to $48 \mathrm{~h}$. The pertinent sequences are shown in Table 1 .

\section{Dual luciferase reporter gene assay}

The target genes of miR-143-5p were analyzed by biology prediction website Targetscan (http://www.targetscan.org). HEK-293T cells (AT-1592, ATCC, Manassas, VA, USA) were plated into a 24-well plate and cultured for $24 \mathrm{~h}$. The total RNA of cells was extracted and reversely transcribed into cDNA. The full-length sequence of eEF2 3'-UTR was obtained by polymerase chain reaction (PCR) amplification with cDNA as the template. According to the sequence of eEF2, the primers were designed (forward primer: 5'-ATGAGGGCAAGATG AAGCTG-3', and reverse primer: 5'-ATGAAGGAC GGGATGTTCAC-3') and amplified with genome extracted from HEK-293T cells as a template. Following the amplification period, the primers were digested by enzyme and cloned into the downstream of pmiRRB carrier luciferase coding gene to obtain eEF2 dual luciferase reporter (DLR) vector, namely pmiRRB-eEF2-3' UTR, which was separately co-transfected with miR-143$5 p$ vector, siRNA-miR-143-5p, or negative control into HEK-293T cells. After transfection for $48 \mathrm{~h}$, the culture medium was aspirated, and cells were rinsed twice with

Table 1 Mimic or inhibitor sequence for cell transfection

\begin{tabular}{ll}
\hline Plasmid & Sequence (5'-3') \\
\hline miR-143-5p mimic & 5'-CCACGTCACGACGTAGAGACC-3' \\
miR-143-5p inhibitor & 5'-CCAGAGATGCAGCACTGCACC-3' \\
miR-143-5p NC & 5'-UCCUCCGAACGUGUCACGUTT-3' \\
\hline
\end{tabular}

Note: miR-143-5p, microRNA-143-5p

$N C$ negative control
PBS. Then cells were then collected and lysed. The luciferase activity was measured with Dual-Luciferase ${ }^{\circ}$ Reporter Assay System (E1910, Promega, Madison, WI, USA). A total of $50 \mu \mathrm{L}$ of firefly luciferase working fluid was added into every $10-\mu \mathrm{L}$ aliquot of cells to examine firefly luciferase activity. Then a $50-\mu \mathrm{L}$ aliquot of renilla luciferase working liquid was added to examine renilla luciferase activity. The ratio of firefly luciferase activity to renilla luciferase activity represented the relative luciferase activity. The experiment was repeated three times.

\section{Reverse transcription quantitative polymerase chain reaction ( $R T-q P C R)$}

The total RNA was extracted from the tissues using the Trizol extraction kit (15596-018, Invitrogen, Grand Island, NY, USA), and the total RNA was extracted from cells using miRNeasy total RNA extraction kit (217004, Beijing Huaxia Ocean Technology Co., Ltd., Beijing, China). The ratio of A260/A280 and concentration of RNA were determined using a Nanodrop ultraviolet spectrophotometer (2000, Thermo, Waltham, MA, USA), with RNA stored at $-80^{\circ} \mathrm{C}$. Following that, the total RNA was reversely transcribed into cDNA according to the instructions of Applied Biosystems StepOneTM and StepOnePlusTM Real-Time PCR Systems (4379704, Applied Biosystems, Foster City, CA, USA). The RT-qPCR assay kit was purchased from Ambion Corporation (NY, CA, USA). RT-qPCR was conducted with PCR instrument (AM1005, Invitrogen, NY, CA, USA), and the conditions were as follows: pre-denaturation at $95^{\circ} \mathrm{C}$ for $3 \mathrm{~min}$ and 35 cycles of denaturation at $95^{\circ} \mathrm{C}$ for $15 \mathrm{~s}$, annealing at $60{ }^{\circ} \mathrm{C}$ for $30 \mathrm{~s}$, and extension at $72^{\circ} \mathrm{C}$ for $30 \mathrm{~s}$. The glyceraldehyde-3-phosphate dehydrogenase (GAPDH) was used as the internal reference of eEF2, mammalian target of rapamycin (mTOR), AMP activated protein kinase (AMPK), B cell lymphoma-2 (Bcl-2), and cyclinD. Besides, U6 was used as the internal reference of miR-143-5p. The primers (Table 2) were synthetized by Shanghai Boya Bio Technology Service Co. Ltd. (Shanghai, China). Every experiment was repeated three times. The reliability of PCR results was evaluated by solubility curve, and the cycle threshold (CT) value (inflection of amplification dynamic curve) was obtained. The relative expression of target gene was calculated by a $2^{-\Delta \Delta C T}$ method [27]. The formula was as follows: $\Delta \Delta \mathrm{Ct}=[\mathrm{Ct}$ (target gene) $-\mathrm{Ct}$ (reference gene) $]$ experimental group - [Ct (target gene) - Ct (reference gene)] control group. This method was applicable for cell experiments.

\section{Western blot analysis}

Total protein was extracted using a total protein extract kit (R0010, Beijing Solarbio Technology Co. Ltd., Beijing, China). The transfected cells were washed using the 
Table 2 Primer sequence for RT-qPCR

\begin{tabular}{|c|c|}
\hline Gene & Sequence \\
\hline \multirow[t]{2}{*}{ miR-143-5p } & F: 5'-GCATCTCTGGTCAGTTGGG-3' \\
\hline & R: 5'-GACCTCAAGAACAGTAT-3' \\
\hline \multirow[t]{2}{*}{ eEF2 } & F: 5'-GAGCTCTCCGAGAACGACC-3' \\
\hline & R: 5'-TACAGTGCCCAGGACAGGAT-3' \\
\hline \multirow[t]{2}{*}{ mTOR } & F: 5'-TTGAGGTTGCTATGACCAGAGAGAA-3' \\
\hline & R: 5'-TTACCAGAAAGGACACCAGCCAATG-3' \\
\hline \multirow[t]{2}{*}{ AMPK } & F: 5'-ATCCGCAGAGAGATCCAGAA-3' \\
\hline & R: 5'-CGTCGACTCTCCTITTCGTC-3' \\
\hline \multirow[t]{2}{*}{$\mathrm{BCl}-2$} & F: 5'-CCTGCCCCAAACAAATATGAAAAG-3' \\
\hline & R: 5'-TTGACCATTTGCCTGAATGTGTG-3' \\
\hline \multirow[t]{2}{*}{ cyclin D } & F: 5'-TCCGCAAGCATGCACAGA-3' \\
\hline & R: 5'-GGTGGGTTGGAAATGAACTTCA-3' \\
\hline \multirow[t]{2}{*}{ Bax } & F: 5'-CGTCTGGCCCTGTATGTCTA-3' \\
\hline & R: 5'-CAACCACCTCTCTGTGCAAT-3' \\
\hline \multirow[t]{2}{*}{ U6 } & F: 5'-CTCGCTTCGGCAGCACA-3' \\
\hline & R: 5'-AACGCTTCACGAATTTGCGT-3' \\
\hline \multirow[t]{2}{*}{ GAPDH } & F: 5'-CGTGATCGAGGGCTGTTGG-3' \\
\hline & R: 5'-CTGCTTCAGTTGGCCTITCG-3' \\
\hline
\end{tabular}

Note: $R T-q P C R$ reverse transcription quantitative polymerase chain reaction, miR-143-5p microRNA-143-5p, eEF2 eukaryotic translation elongation factor 2 , AMPK AMP activated protein kinase, BCl-2 B cell lymphoma-2, $m T O R$ mammalian target of rapamycin, GAPDH glyceraldehyde-3-phosphate dehydrogenase, $F$ forward, $R$ reverse, Bax Bcl-2 Associated $\mathrm{X}$ protein

precooling PBS three times. The protein lysate $(60 \%$ radio immunoprecipitation assay [RIPA] lysis buffer $+39 \%$ sodium dodecyl sulfate $[\mathrm{SDS}]+1 \%$ protease inhibitors) was added into every cell bottle, and the mixture was lysed on ice for $30 \mathrm{~min}$ in the EP tube. Then cells were centrifuged at $32,608 \times g$ in the high-speed freezing centrifuge for $30 \mathrm{~min}$ at $4{ }^{\circ} \mathrm{C}$, and the supernatant was collected and placed on the icebox to measure protein concentration using bicinchoninic acid (BCA) method. Subsequently, $10 \%$ separation gel and 5\% spacer gel were prepared using sodium dodecyl sulfate-polyacrylamide gel electrophoresis (SDS-PAGE) kit, and the protein was separated using electrophoresis on polyacrylamide gel. Following that, protein was transferred onto a nitrocellulose membrane. The membrane was blocked with $5 \%$ bovine serum albumin (BSA) at room temperature for $1 \mathrm{~h}$ and incubated with primary antibodies of rabbit anti eEF2 (1:10000, ab75748), p-AMPK (1:2000, ab133448), Bax (1:1000, ab32503), p-mTOR (1:5000, ab137133), cyclinD (1:10000, ab134175), Bcl-2 (1:1000, ab196495), t-AMPK (1:2000, ab32047), t-mTOR (1:2000, ab2732), and GAPDH (1:1000, ab9485). All the above antibodies were purchased from Abcam Inc. (Cambridge, MA, USA). The following day, the membrane was incubated with the secondary antibody, goat anti-rabbit IgG (1:2000, ab205718, Abcam Inc., Cambridge, MA, USA) at $4{ }^{\circ} \mathrm{C}$ for $1 \mathrm{~h}$. The proteins were visualized with a developing agent and imaged using a Bio-rad imaging system (MG8600, Beijing Thmorgan Biotechnology Co., Ltd., Beijing, China). Quantitative analysis was conducted using IPP7.0 software (Media Cybernetics, Silver Springs, MD, USA). The ratio of gray value of eEF2, p-AMPK, p-mTOR, Bcl-2, cyclinD, Bax, $\mathrm{t}-\mathrm{AMPK}$, and $\mathrm{t}$-mTOR protein bands to that of the internal reference GAPDH protein band represented the protein levels of genes respectively. The procedures were also applicable for cell experiments.

\section{3-(4,5-Dimethylthiazol-2-yl)-2,5-diphenyltetrazolium bromide (MTT) assay}

The transfected cells in each group were incubated in RPMI 1640 culture medium containing 10\% FBS based on the predetermined concentration with $5 \% \mathrm{CO}_{2}$ at $37^{\circ} \mathrm{C}$ for $48 \mathrm{~h}$. Cells in the logarithmic growth phase were collected for the following experiment. The cell suspension was transferred into a centrifuge tube and then triturated evenly using a sterile straw. Single-cell suspension was stained by trypan blue staining solution. The number of living cells was counted. The living cells were seeded into a 96 -well plate $(180 \mu \mathrm{L}$ of cells per well) at a density of $1 \times 10^{4}$ cells/well. Afterwards, cells were cultured at $37^{\circ} \mathrm{C}$ with $5 \% \mathrm{CO}_{2}$ for 16 to $48 \mathrm{~h}$. Each well was incubated with $20 \mu \mathrm{L}$ of $5 \%$ MTT under conditions void of light. The 96 -well plate was cultured in a $5 \% \mathrm{CO}_{2}$ incubator at $37^{\circ} \mathrm{C}$ under conditions void of light for $4 \mathrm{~h}$. After that, the cells were centrifuged at $179 \times g$ for $10 \mathrm{~min}$ with the supernatant removed. Then, $100 \mu \mathrm{L}$ dimethyl sulfoxide (DMSO) solution was used to dissolve the crystal fully under conditions void of light for $10 \mathrm{~min}$. Fifteen minutes later, optical density (OD) value was detected at $570 \mathrm{~nm}$ using enzymelinked immunosorbent assay (ELISA) reader (SAF-680T, Multiskan GO, Thermo, Waltham, MA, USA). Cell growth curve was plotted with time as the abscissa and $\mathrm{OD}$ value as the ordinate.

\section{Flow cytometry}

After transfection of $24 \mathrm{~h}$, the cells were collected, washed with cold PBS three times, centrifuged with the supernatant removed, and then resuspended with PBS to adjust cell density to $1 \times 10^{5} / \mathrm{mL}$. Cells were then fixed by $1 \mathrm{~mL}$ of $75 \%$ ice ethanol (precooled at $-20^{\circ} \mathrm{C}$ ) at $4{ }^{\circ} \mathrm{C}$ for $1 \mathrm{~h}$. After that, they were centrifuged and washed with PBS two times. Cells were incubated with $100 \mu \mathrm{L}$ RNase A under conditions void of light, water-bathed at $37^{\circ} \mathrm{C}$ for $30 \mathrm{~min}$, and stained with $400 \mu \mathrm{L}$ of propidium iodide (PI) (D0820, Sigma, San Francisco, CA, USA). They were incubated at $4{ }^{\circ} \mathrm{C}$ under conditions void of light for $30 \mathrm{~min}$. After that, the red fluorescence at the wavelength of $488 \mathrm{~nm}$ was recorded by flow cytometry (Gallios, Beckman Coulter, S.Kraemer Boulevard Brea, 
CA, USA) to detect cell cycle. After transfection for 48 $h$, cells were treated with ethylenediamine tetraacetic acid (EDTA)-free trypsin and centrifuged to discard the supernatant. Cells were rinsed by cold PBS three times and centrifuged with the supernatant discarded. In accordance with the instructions of Annexin-V-FITC kit (4030ES20, Sigma, SF, CA, USA), the Annexin-V-FITC/PI staining solution was prepared with Annexin-V-FITC, PI, (2-hydroxyethyl)-1-piperazineethanesulfonic acid (HEPES) in the proportion of 1:2:50. The $1 \times 10^{6}$ cells were resuspended in every $100-\mu \mathrm{L}$ aliquot of staining solution. Cells were then incubated at room temperature for $15 \mathrm{~min}$ and then added with $1 \mathrm{~mL}$ of HEPES. The cells were excited at $488 \mathrm{~nm}$, the FITC fluorescence was measured at $525 \mathrm{~nm}$, and PI fluorescence was measured at $620 \mathrm{~nm}$ with a band-pass filter.

Senescence-associated $\beta$-galactosidase (SA- $\beta$-gal) staining The senescence of NP cells was assessed by SA- $\beta$-gal staining. NP cells in the control group and experimental groups were collected and seeded into six-well plates at a density of $3 \times 10^{5}$ cells/well. Upon reaching $70 \%$ confluence, cells were washed using PBS and fixed by 1 $\mathrm{mL}$ SA- $\beta$-gal staining solution for $15 \mathrm{~min}$ at room temperature. The cells were washed three times by PBS ( $3 \mathrm{~min}$ per wash). The cells were stained with $1 \mathrm{~mL}$ SA- $\beta$-gal staining solution and then sealed with a preservative film at $37^{\circ} \mathrm{C}$ overnight. The SA- $\beta$-gal-stained cells (the cytoplasm stained in dark blue) and total cells were counted under an optical microscope. The SA- $\beta$-gal-positive rate of NP cells = the number of SA- $\beta$-gal-stained NP cells/the number of total cells. The cytoplasm of SA- $\beta$-gal-positive cells presented dark blue staining.

\section{Statistical analysis}

Statistical analysis was conducted using SPSS 17 (SPSS, Chicago, IL, USA), and data were expressed by mean \pm standard deviation. Comparison of data between two groups was conducted using a $t$-test and that of data among multiple groups was performed by one-way analysis of variance (ANOVA). Disc height index and rate of disc height change were analyzed by one-way ANOVA. The grade of IDD was analyzed by kappa. If the kappa value was $0-0.2$, it means the consistency deviation was comparatively large and the result was very poor. If the kappa value was $0.21-04$, it means the result was poor. If the kappa value was $0.41-0.60$, it means the result was ordinary. If the kappa value was 0.61-0.8, it means the consistency of the result was comparatively good. Besides, if the kappa value was over 0.81 , the result was basically the same and the result was reliable. $p<0.05$ was considered statistically significant.

\section{Results}

\section{IDD models are successfully established}

Among the 30 rat coccygeal vertebras with puncture, IVD of 16 rats degenerated in the second week after puncture at a rate (modeling success rate) of 53\%. In the fourth week, the degenerated number increased to 25 with a rate of $83 \%$. In the second week after puncture, the mean DHI (\%) was $86.44 \pm 3.00$, RDHC was 0.75 , and the mean score of IDD was 3.35 , with an obvious difference compared with that before the puncture. In the fourth week after puncture, the mean DHI (\%) was $69.00 \pm 2.37$ and the RDHC was 0.7 which was significantly lower when compared to that of the second week. T2-weighted imaging demonstrated that the IVD construction was damaged and that the signal was weak with the color of bright white turning into gloomy gray along with the diminished or collapsed disc height. Also, in the fourth week, the mean score of the IDD was 5.07, and the degree of degeneration became worse after the puncture. According to the data shown in Table 3, in the second week after puncture, the mean DHI (\%) was $86.44 \pm 3.00$ was significantly reduced when compared with that before puncture. The mean RDHC was $0.75 \pm 0.03$ with statistical difference compared with the value before puncture. In the fourth week after puncture, the mean DHI $(\%)$ was $69.00 \pm 2.37(p<0.001)$ and the mean RDHC was $0.70 \pm 0.02 \quad(p<0.001)$, which statistically differed from former data before the puncture.

Morphological characteristics of IVD tissues were observed after Safranin $\mathrm{O}$ staining and HE staining. As depicted in Fig. 1a, b, the cartilage of normal IVD tissues exhibited a clear and regular structure, with a large area of red staining in the NP and cartilage endplate, and rich proteoglycans. By contrast, degenerative IVD tissues showed a disordered structure, lighter red staining, narrowed IVD space, and derangement of annulus fibrosus. HE staining results in Fig. 1c-f displayed that in rat caudal IVD, the nearly round complete NP occupied more than half area of the IVD, and the stellate NP cells were equally distributed in the nucleus pulposus. The IVD degenerated in the IDD rats with NP shrank, and the NP cells exhibited vacuolar degeneration with cluster distribution. Taken together, IDD had a close correlation with the IVD degeneration and NP shrank.

\section{eEF2 protein is lowly expressed in degenerative IVD tissues}

Following the establishment of the IDD models, immunohistochemistry was used for examining the eEF2 protein positive rate, so as to shed light on the effect of eEF2 in IDD. The result revealed that a eEF2-positive particle was brownish yellow in notochord cells and 
Table 3 Degeneration of rat caudal IVD at different time points

\begin{tabular}{lllllll}
\hline Time point & Non-degenerative IVD & Total degenerative IVD & Degenerative score & Degenerative rate & DHI (\%) & RDHC \\
\hline At the beginning & 30 & 0 & 0 & 0 & $100 \pm 0$ \\
The 2nd week & 14 & 16 & $3.35 \pm 0.30^{*}$ & $53 \%^{*}$ & $86.44 \pm 3.00^{*}$ & $0.75 \pm 0.03^{*}$ \\
The 4th week & 5 & 25 & $5.07 \pm 0.41^{*}$ & $83 \%^{*}$ & $69.00 \pm 2.37^{*}$ & $0.70 \pm 0.02^{*}$ \\
\hline
\end{tabular}

Note: $n=15$

$D H I$ disc height index, $R D H C$ rate of disc height change, IVD intervertebral disc

${ }^{*} p<0.05$ vs. the data obtained at the beginning; the comparison of data was conducted using a $t$-test

chondrocytes. The positive rate of eEF2 protein expression in NP cells of the normal IVD was $65.7 \pm 6.0 \%$, while being $43.1 \pm 3.5 \%$ in the degenerative IVD. The positive rate of eEF2 protein expression in the normal IVD was much higher than that in degenerative IVD $(p<0.05)$ (Fig. 2a, b). Based on the result, it was concluded that eEF2 protein expressed at a low level in degenerative IVD.

\section{IDD is associated with increased NP cell senescence}

SA- $\beta$-gal staining was carried out to observe senescent changes in NP cells. As shown in Fig. 3, the cytoplasm in normal IVD was stained dark blue without clear vacuoles and no obvious staining in the nucleus. The degenerative IVD tissues showed a much higher positive staining rate than the normal IVD tissues $(p<0.01)$.

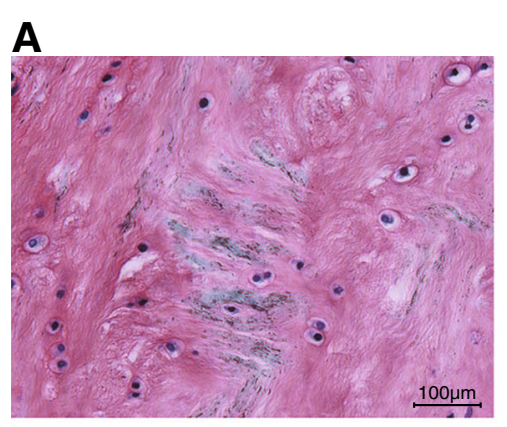

B
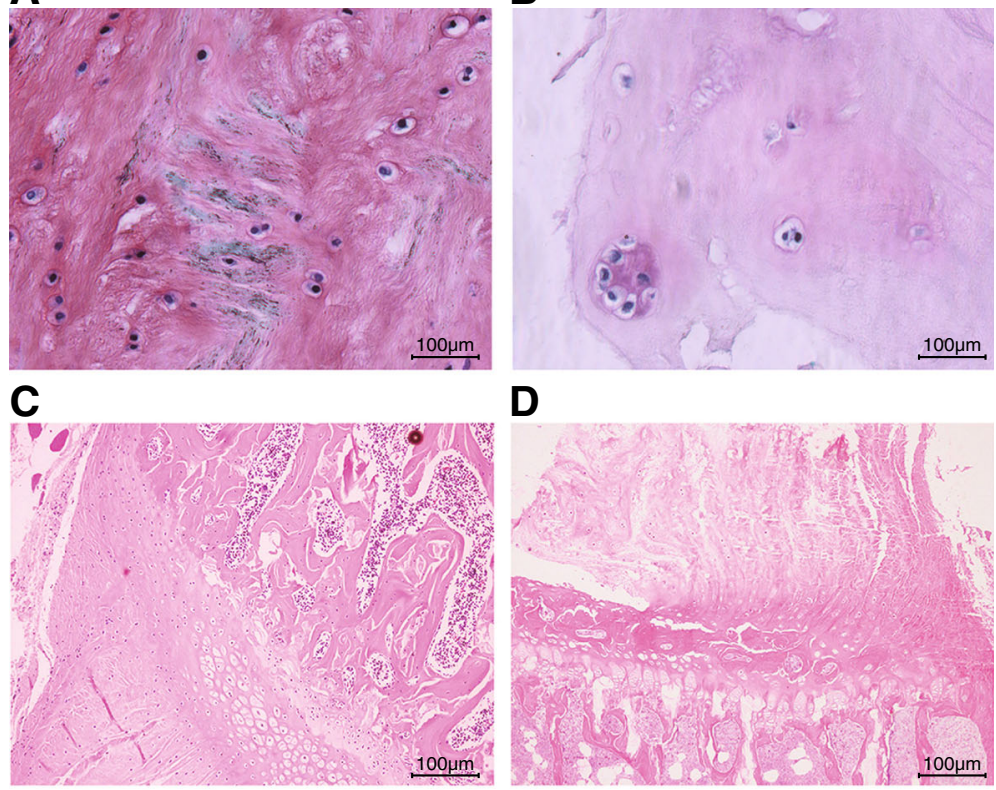

D

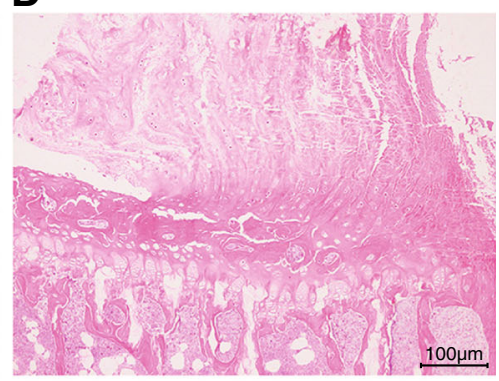

E

F
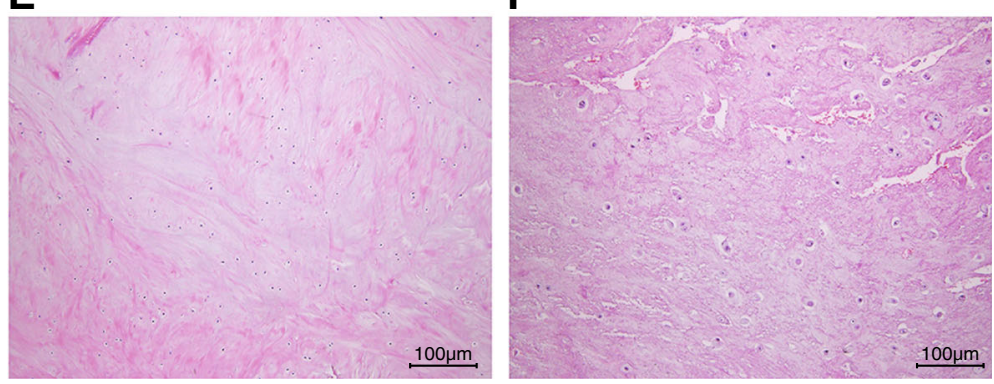

Fig. 1 The induction of IDD in rats exhibits degenerative IVD and shrank NP. a Safranin O staining images of normal IVD tissues and NP (× 100). b Safranin O staining images of degenerative IVD tissues and NP. c HE staining images of normal IVD tissues. $\mathbf{d} H E$ staining images of degenerative IVD tissues. e HE staining images of NP in normal IVD tissues. $\mathbf{f}$ HE staining images of NP in degenerative IVD tissues. HE, hematoxylin-eosin; IVD, intervertebral disc; IDD, intervertebral disc degeneration; NP, nucleus pulposus 

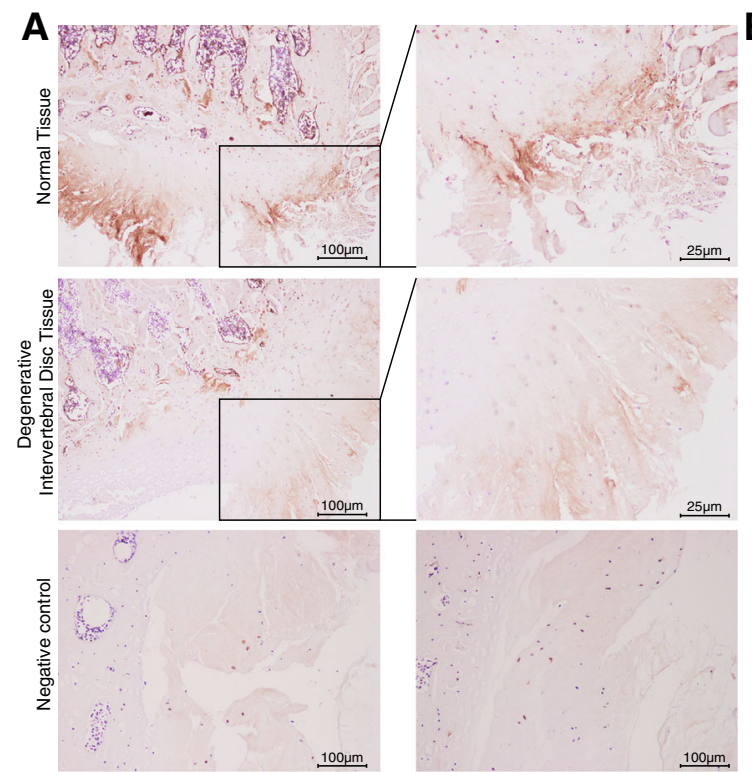

B

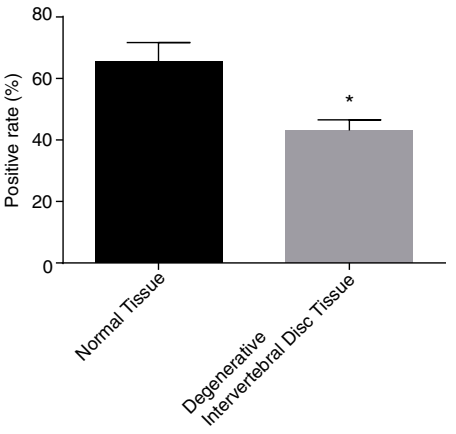

Fig. 2 eEF2 protein is expressed at a low level in degenerative IVD. a Immunohistochemistry images of eEF2 protein expression in normal IVD and degenerative IVD ( $\times 100$ in left panel, $\times 400$ in right panel). eEF2-positive particle is stained brownish yellow in notochord cells and chondrocytes. b Positive rate of eEF2 protein expression in normal IVD and degenerative IVD; $n=15$; positive rate represents the mean value of the percentage of positively stained cells in total cells; data were expressed by mean \pm standard deviation; comparison of data between two groups was conducted using a $t$-test; ${ }^{*}, p<0.05$ vs. normal IVD; IVD, intervertebral disc; IDD, intervertebral disc degeneration; eEF2, eukaryotic elongation factors-2

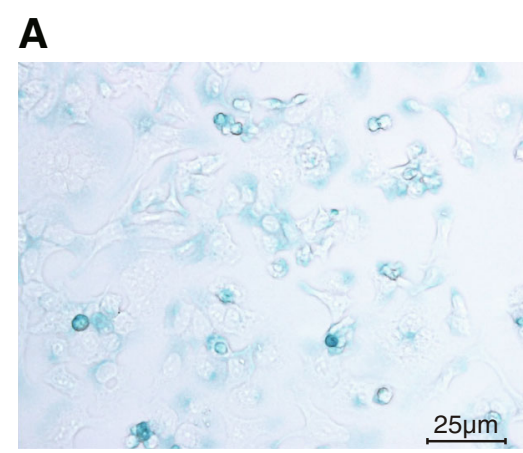

Normal Tissue

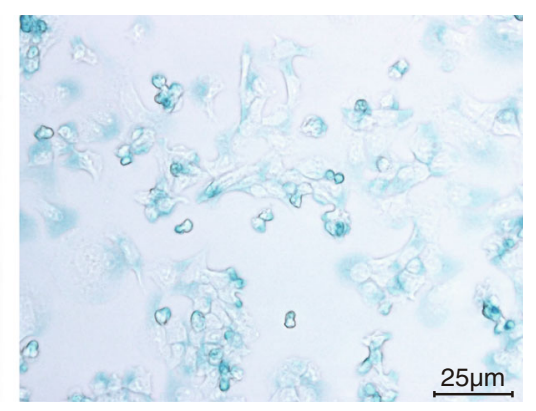

Degenerative Intervertebral Disc Tissue

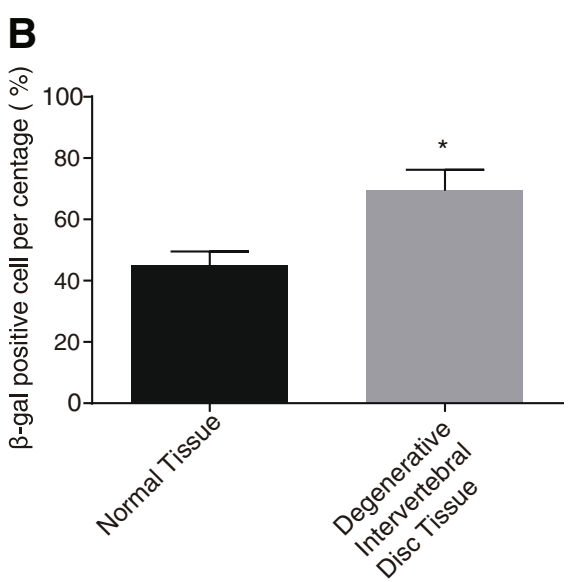

Fig. 3 Degenerative IVD shares a close association with increased NP cell senescence. a SA- $\beta$-gal staining images of senescent NP cells in normal IVD and degenerative IVD under a microscope $(\times 400)$; dark blue-stained cells were senescent ones. b The positive rate of SA- $\beta$-gal staining in normal IVD and degenerative IVD; the positive rate of SA- $\beta$-gal staining represents the percentage of dark blue-stained NP cells in total NP cells; the experiment was repeated three times independently; data were expressed by mean \pm standard deviation; comparison of data between two groups was conducted using a t-test; *,$p<0.05$ vs. normal IVD; IVD, intervertebral disc; NP, nucleus pulposus; SA- $\beta$-gal, senescence-associated $\beta$-galactosidase 
Therefore, it was concluded that IVD degeneration had a close correlation with increased NP cell senescence.

miR-143-5p and AMPK are upregulated while eEF2 is downregulated and cartilage differentiation is inhibited in degenerative IVD tissues

The mRNA and protein levels of cartilage differentiationrelated and AMPK signaling pathway-related genes in normal IVD and degenerative IVD were detected using RT-qPCR (Fig. 4a) and Western blot analysis (Fig. 4b, c). When compared to the normal IVD, degenerative IVD showed significantly decreased mRNA and protein levels of mTOR, Bcl-2, cyclinD and eEF2, and p-mTOR/ $\mathrm{t}$-mTOR protein level ratio, while obviously increased mRNA and protein levels of Bax and AMPK, p-AMPK/ t-AMPK protein level ratio, and miR-143-5p expression.

The protein levels of cartilage differentiation-related genes in normal IVD and degenerative IVD were detected using Western blot analysis (Fig. 4d). When compared to the normal IVD, degenerative IVD showed significantly decreased levels of COL2, ACAN, and DCN proteins $(p<0.05)$.

Therefore, these results demonstrated that miR-143-5p highly expressed and AMPK signaling pathway activation was induced in degenerative IVD, while eEF2 lowly expressed and cartilage differentiation was inhibited.

\section{eEF2 is a target gene of miR-143-5p}

Bioinformatics prediction website Targetscan was used to predict the relationship between miR-143-5p and eEF2, and dual luciferase reporter gene assay was carried out to confirm the prediction. As shown in Fig. 5a, miR-143-5p could target eEF2. In order to prove whether the eEF2 is a direct target gene of miR-143-5p, the recombinant plasmids of luciferase reporter vector-eEF2-Wt and eEF2-mut were first constructed, with inserted eEF2 mRNA3'-UTR. eEF2-mut referred to the mutation at the predicted binding site of eEF2 and miR-143-5p, which was used to identify the binding of miR-143-5p and eEF2. From a DLR gene system, in the miR-143-5p transfection group, the eEF2-3'-UTR co-transfection luciferase activity dropped by $42 \%$ approximately when compared to that of the other groups $(p<0.05)$ (Fig. $5 \mathrm{~b})$, while mutant eEF2-mut-3'-UTR luciferase activity showed no significant decrease $(p>0.05)$, which indicated that eEF2 was a potential target gene of miR-143-5p. Therefore, miR-143-5p inhibited the activity of eEF2.

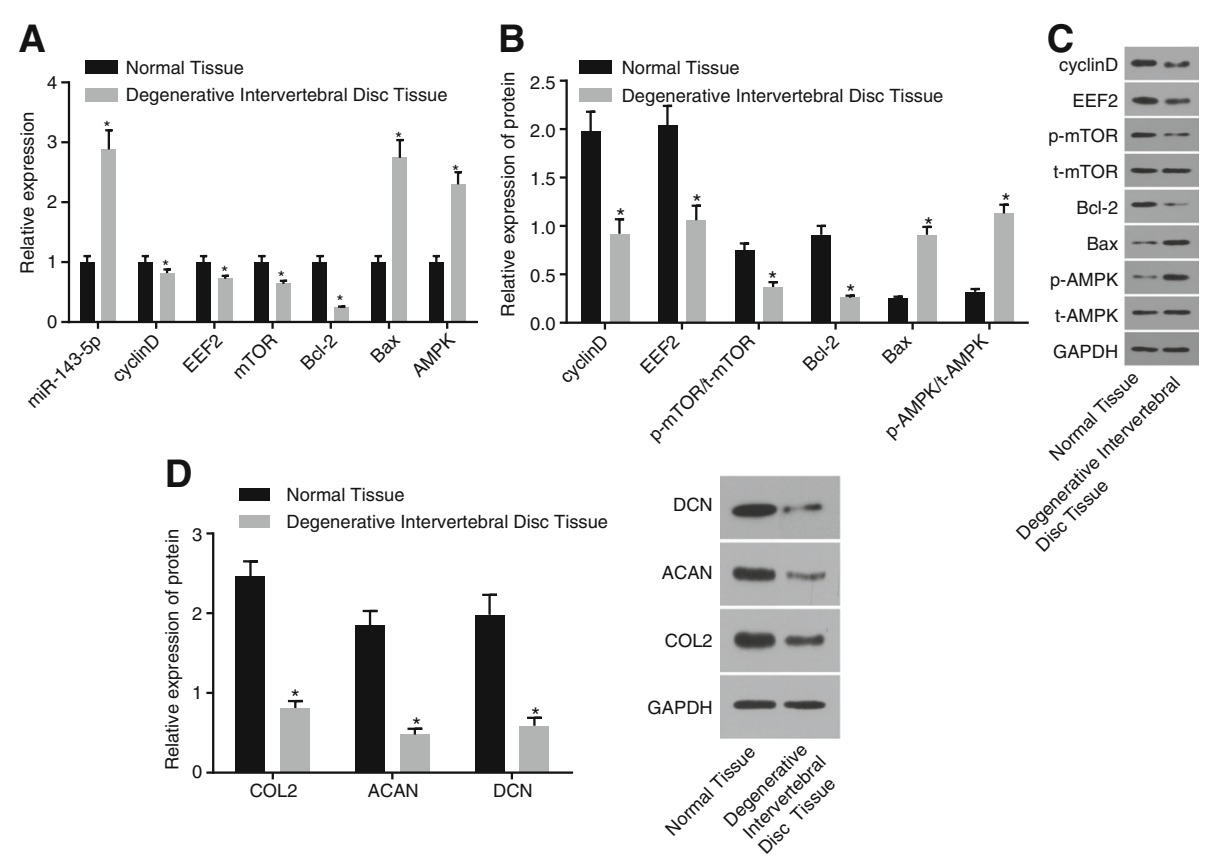

Fig. 4 IDD rats exhibit upregulated miR-143-5p and activated AMPK signaling pathway yet inhibited NP cell differentiation and eEF2. a miR-143-5p expression and mRNA expression of Bax, AMPK, mTOR, Bcl-2, cyclinD, and eEF2 in normal IVD and degenerative IVD. b, $\mathbf{c}$ Protein levels and bands of Bax, AMPK, mTOR, BCl-2, cyclinD, and eEF2 in normal IVD and degenerative IVD. $\mathbf{d}$ Protein levels of COL2, ACAN, and DCN in normal IVD and degenerative IVD; the experiment was repeated three times independently; data were expressed by mean \pm standard deviation; comparison of data between two groups was conducted using a $t$-test; ${ }^{*}, p<0.05$ vs. normal IVD; miR-143-5p, microRNA-143-5p; IVD, intervertebral disc; eEF2, eukaryotic translation elongation factor 2; AMPK, AMP activated protein kinase; Bax, Bcl-2 Associated X protein; Bcl-2, B cell lymphoma-2; mTOR, mammalian target of rapamycin; GAPDH, glyceraldehyde-3-phosphate dehydrogenase; COL2, collagen type II; ACAN, aggrecan; DCN, decorin 


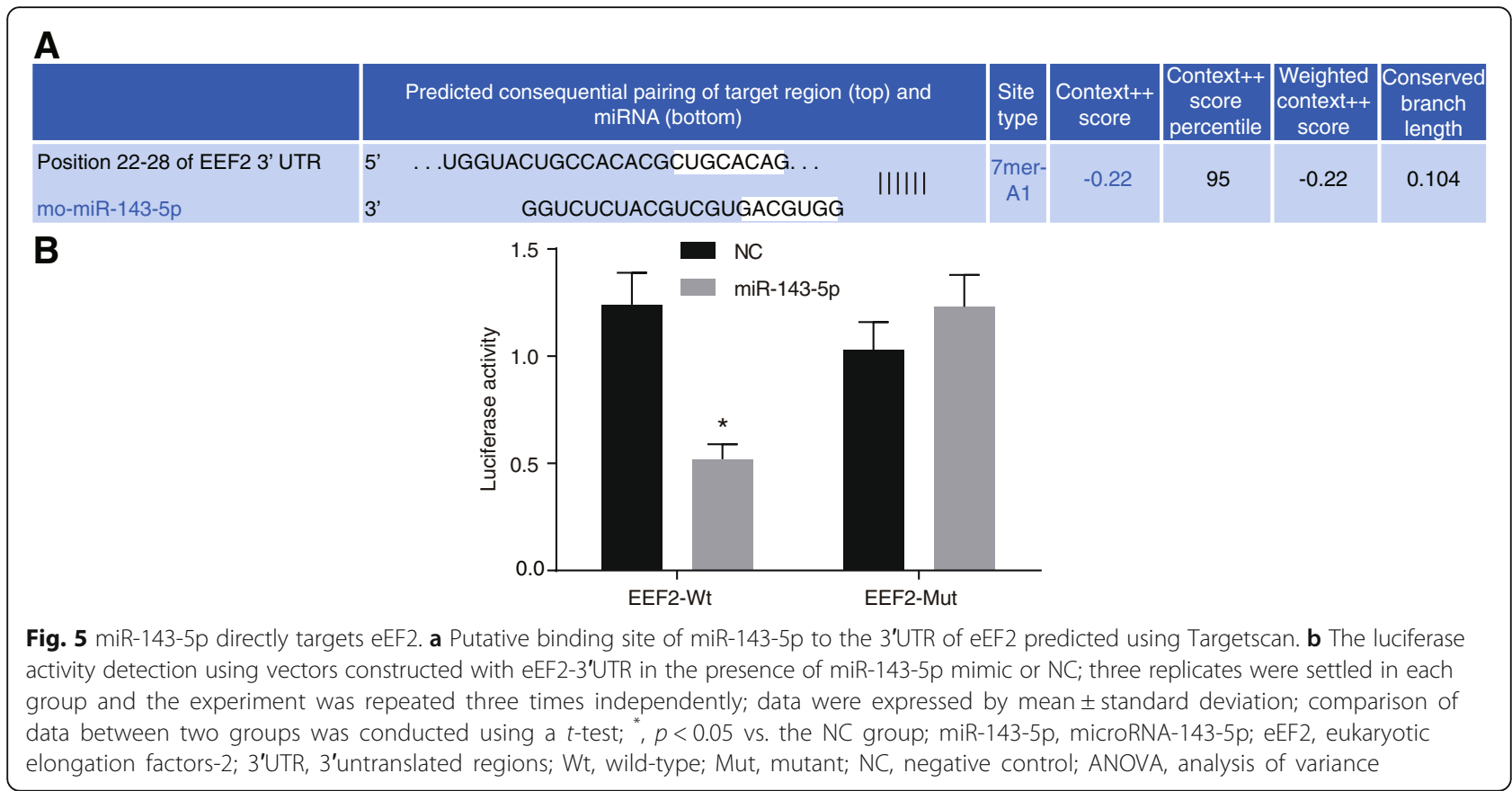

miR-143-5p-mediated eEF2 inhibition activates AMPK signaling pathway in NP cells

The potential effects of miR-143-5p targeting eEF2 on the APMK signaling pathway were analyzed using gainand loss-of-function approaches. The NP cells from degenerative IVD were transfected with miR-143-5p mimic or inhibitor. RT-qPCR (Fig. 6a) showed the miR-143-5p expression was elevated after the NP cells from degenerative IVD transfected with miR-143-5p mimic while that was reduced after transfection with miR-143-5p inhibitor $(p<0.05)$. As shown by the obtained RT-qPCR and Western blot analysis results (Fig. $6 \mathrm{a}-\mathrm{c}$ ), when compared to those of the blank and NC groups, the mRNA and protein levels of Bax (apoptotic factor), and p-AMPK/t-AMPK protein level ratio were significantly increased, while the mRNA and protein levels of Bcl-2 (anti-apoptotic factor), cyclinD and eEF2, and p-mTOR/ $\mathrm{t}$-mTOR protein level ratio significantly decreased in the miR-143-5p mimic group $(p<0.05)$. However, in the miR-143-5p inhibitor group, the mRNA and protein levels of Bax and $\mathrm{p}-\mathrm{AMPK} / \mathrm{t}-\mathrm{AMPK}$ protein level ratio were significantly decreased and that of Bcl-2, cyclinD and eEF2, and $\mathrm{p}-\mathrm{mTOR} / \mathrm{t}-\mathrm{mTOR}$ protein level ratio were significantly elevated when compared to that of the blank and NC groups $(p<0.05)$. This data revealed that miR-143-5p negatively regulated eEF2 and activated the AMPK signaling pathway in NP cells. Additionally, AICAR was applied to induce the activation of AMPK signaling pathway. The mRNA and protein levels of those genes or proteins in the AICAR group exhibited similar results of the aforementioned genes or proteins as that in the miR-143-5p mimic group. In the miR-143-5p inhibitor + AICAR group, the expression of the abovementioned genes showed no significant difference when compared to that of the blank and $\mathrm{NC}$ groups $(p>0.05)$, suggesting that the contributory effect of miR-143-5p on NP cell apoptosis depended on the activation of the AMPK signaling pathway.

Inhibition of miR-143-5p promotes NP cell differentiation by inactivating the AMPK signaling pathway

NP cell differentiation following transfection was assessed using Western blot analysis. As shown in Fig. 7, when compared to those of the control group, the protein levels of CLO2, ACAN, and DCN in NP cells were decreased in the remaining groups $(p<0.05)$. There was no obvious significance in protein levels of CLO2, ACAN, and DCN between the blank and NC groups $(p>0.05)$. When compared to those of the blank and NC groups, the protein levels of CLO2, ACAN, and DCN were significantly elevated in the miR-143-5p inhibitor group $(p<0.05)$ while significantly reduced in the miR-143-5p mimic and AICAR groups $(p<0.05)$. The protein levels of CLO2, ACAN, and DCN were significantly diminished in the miR-143-5p inhibitor + AICAR group as compared with those in the miR-143-5p inhibitor group $(p<0.05)$, while also displaying no clear difference when compared to those of the blank group $(p>0.05)$. The data suggested that inhibition of miR-143-5p promoted the differentiation of NP cells via inactivation of the AMPK signaling pathway. 

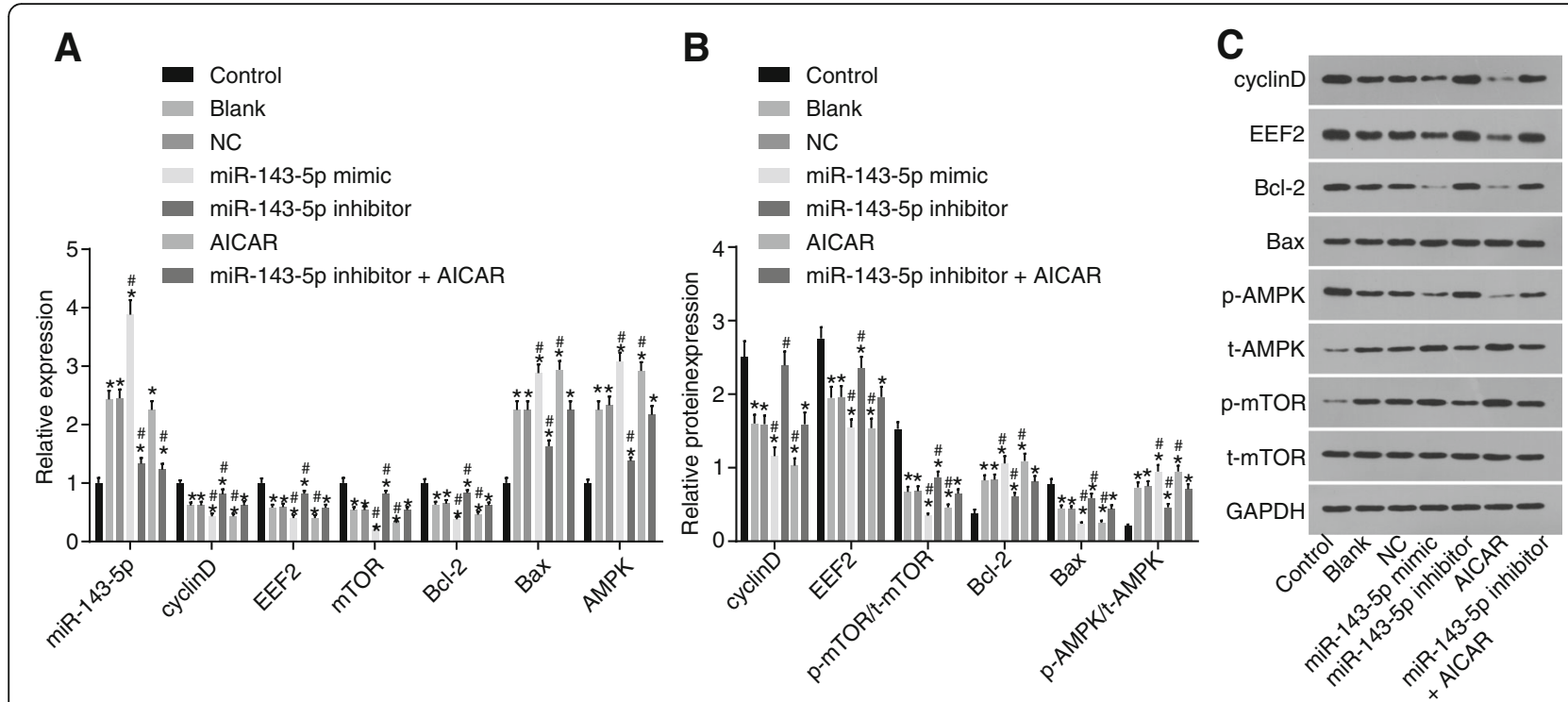

Fig. 6 MiR-143-5p suppresses eEF2 and activates the AMPK signaling pathway in NP cells. a miR-143-5p expression and mRNA expression of cyclinD, eEF2, mTOR, Bcl-2, Bax, and AMPK in NP cells from degenerative IVD treated with miR-143-5p mimic, inhibitor, or AICAR determined by RT-qPCR. b, c Protein levels and bands of cyclinD, eEF2, mTOR, Bcl-2, Bax, and AMPK in NP cells treated with miR-143-5p mimic, inhibitor, or AICAR determined by Western blot analysis; AICAR was the activator of the AMPK signaling pathway; the experiment was repeated three times independently; data were expressed by mean \pm standard deviation; comparison of data among multiple groups was analyzed using one-way ANOVA; ${ }^{*}, p<0.05$ vs. the control group (NP cells from normal IVD); ${ }^{\#}, p<0.05$ vs. the blank group (NP cells from degenerative IVD without transfection) and the NC group (NP cells from degenerative IVD transfected with NC sequence); miR-143-5p mimic group refers to NP cells from degenerative IVD transfected with miR-143-5p mimic; miR-143-5p inhibitor group refers to NP cells from degenerative IVD transfected with miR143-5p inhibitor; AICAR group refers to NP cells from degenerative IVD treated with AMPK signaling pathway activator, AICAR; miR-143-5p inhibitor + AICAR group refers to NP cells of degenerative IVD treated with AICAR and transfected with miR-143-5p inhibitor. NC, negative control; miR-143-5p, microRNA-143-5p; eEF2, eukaryotic translation elongation factor 2; AMPK, AMP activated protein kinase; Bax, BCl-2 Associated X protein; Bcl-2, B cell lymphoma-2; mTOR, mammalian target of rapamycin; GAPDH, glyceraldehyde-3-phosphate dehydrogenase; NP, nucleus pulposus; ANOVA, analysis of variance

Inhibition of miR-143-5p induces NP cell proliferation via the inactivation of the AMPK signaling pathway

NP cell proliferation was measured by means of MTT assay, and the results (Fig. 8a) indicated that in contrast to the cell proliferation rate at the 24th hour, the cell proliferation rate at the 48th hour and 72nd hour displayed significant difference in each group $(p<0.05)$. When compared to that of the control group, the cell viability was significantly decreased in the miR-143-5p mimic, miR-143-5p inhibitor, AICAR, and miR-143-5p inhibitor + AICAR groups $(p<0.05)$. There was no significant difference in NP cell viability between the blank and NC groups $(p>0.05)$. When compared to that of the blank group and NC group, the cell viability decreased in the miR-143-5p mimic and AICAR groups ( $p$ $<0.05$ ), and significantly increased in the miR-143-5p inhibitor group $(p<0.05)$. Besides, there was no difference in the miR-143-5p inhibitor + AICAR group $(p>0.05)$.

Flow cytometry analysis was further carried out to confirm the cell cycle, the results of which in Fig. 8 b, c suggested that, when compared to the control group, the blank, NC, miR-143-5p mimic, AICAR, miR-143-5p inhibitor, and miR-143-5p inhibitor + AICAR groups exhibited prolonged G0/G1 phase (increased cell proportion at G0/G1 phase), but shortened $S$ phase (decreased cell proportion at G0/G1 phase) $(p<0.05)$. When compared to that of the blank and NC groups, G0/G1 phase shortened (cell proportion decreased) and S phase lengthened (cell proportion increased) in the miR-143-5p inhibitor group, while G0/G1 phase lengthened (cell proportion increased). At the same time, the $\mathrm{S}$ phase was shortened (cell proportion decreased) in the miR-143-5p mimic and AICAR groups $(p<0.05)$, and no significant difference was found in the miR-143-5p inhibitor + AICAR group $(p>0.05)$. There was no significant difference in cell proportion in the G2 phase among all groups $(p>0.05)$. Based on these results, it was concluded that miR-143-5p depletion promoted NP cell proliferation and cell cycle entry by inhibiting the AMPK signaling pathway.

\section{Inhibition of miR-143-5p suppresses NP cell apoptosis and senescence by inactivating the AMPK signaling pathway}

Flow cytometry analysis was also employed to test cell apoptosis. The results showed that when compared to that 

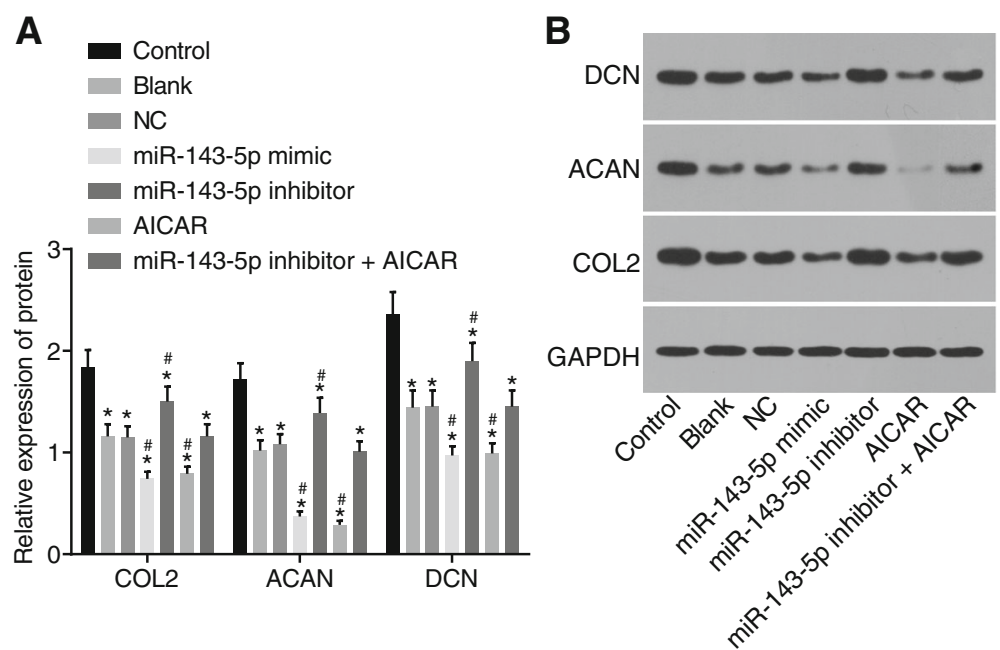

Fig. 7 Inhibition of miR-143-5p facilitates NP cell differentiation by inactivating the AMPK signaling pathway. a Protein levels of CLO2, ACAN, and DCN in NP cells from degenerative IVD treated with miR-143-5p mimic, inhibitor, or AICAR. b Protein bands of CLO2, ACAN, and DCN in NP cells from degenerative IVD treated with miR-143-5p mimic, inhibitor, or AICAR; AICAR was the activator of the AMPK signaling pathway; the experiment was repeated three times independently; data were expressed by mean \pm standard deviation; data among multiple groups were analyzed using one-way ANOVA; ${ }^{*}, p<0.05$ vs. the control group (NP cells from normal IVD); ${ }^{*}, p<0.05$ vs. the blank group (NP cells from degenerative IVD without transfection) and the NC group (NP cells from degenerative IVD transfected with NC sequence); miR-143-5p mimic group refers to NP cells from degenerative IVD transfected with miR-143-5p mimic; miR-143-5p inhibitor group refers to NP cells from degenerative IVD transfected with miR-143-5p inhibitor; AICAR group refers to NP cells from degenerative IVD treated with AMPK signaling pathway activator, AICAR; miR-143-5p inhibitor + AICAR group refers to NP cells of degenerative IVD treated with AICAR and transfected with miR-143-5p inhibitor. miR-143-5p, microRNA-143-5p; COL2, collagen type II; ACAN, aggrecan; DCN, decorin; GAPDN, glyceraldehyde-3-phosphate dehydrogenase; NC, negative control; AMPK, AMP activated protein kinase; NP, nucleus pulposus; ANOVA, analysis of variance

of the control group, the apoptotic rate was significantly increased in the blank, NC, miR-143-5p mimic, miR-143-5p inhibitor, AICAR, and miR-143-5p inhibitor + AICAR groups $(p<0.05)$. When compared to that of the blank and $\mathrm{NC}$ groups, cell apoptotic rate was reduced in the miR-143-5p inhibitor group and increased in the miR-143-5p mimic and AICAR groups $(p<0.05)$. There were no significant differences in cell apoptotic rate among the miR-143-5p inhibitor + AICAR, blank, and NC groups $(p>0.05)$ (Fig. 9a, b).

SA- $\beta$-gal staining was carried out to observe NP cell senescence. From the results of SA- $\beta$-gal staining, the cytoplasm of NP cells from normal IVD presented dark blue without any obvious vacuoles, but no obvious staining in nucleus was observed under the optical microscope (Fig. 9c, d). Positive rate in NP cells from degenerative IVD was significantly higher than that in the NP cells from normal IVD $(p<0.05)$. When compared to that of the control group, cell senescence significantly increased in the remaining groups $(p<0.05)$. In contrast to the blank and NC groups, cell senescence was diminished in the miR-143-5p inhibitor group $(p<0.05)$, while significantly increased in the miR-143-5p mimic and AICAR groups $(p<0.05)$. No significant difference was observed in the cell senescence among the blank, NC, and miR-143-5p inhibitor + AICAR groups $(p>0.05)$. Taken together, miR-143-5p inhibition impeded NP cell apoptosis and senescence by inhibiting the AMPK signaling pathway.

\section{Discussion}

Human IDD is associated with dysfunction of NP cells, including differentiation, migration, proliferation, and apoptosis, and epigenetic processes and genetic background also are risk factors of IDD [28]. Furthermore, abnormal expression of miRNAs has been linked with various musculoskeletal disorders and also has a vital role to play in the pathogenesis of IDD [29]. However, the detailed mechanism of miR-143-5p in IDD remains poorly understood. The purpose of this study was to illustrate that miR-143-5p targeting the eEF2 gene could mediate IDD. Collectively, the data of this study revealed that miR-143-5p was highly expressed in rats with IDD while the inhibition of miR-143-5p was observed to inhibit NP cell senescence and apoptosis and promote cell proliferation and differentiation via repressing the activity of the AMPK signaling pathway.

Initially, based on the findings of this study, miR-143-5p was found to be expressed at a high level in degenerative IVD. Recent studies have confirmed that miR-143 is a muscle-enriched miRNA capable of mediating the myoblast differentiation and muscle aging [30]. Another previous study noted that the overexpression of miR-143-5p accelerates cell migration, proliferation, 


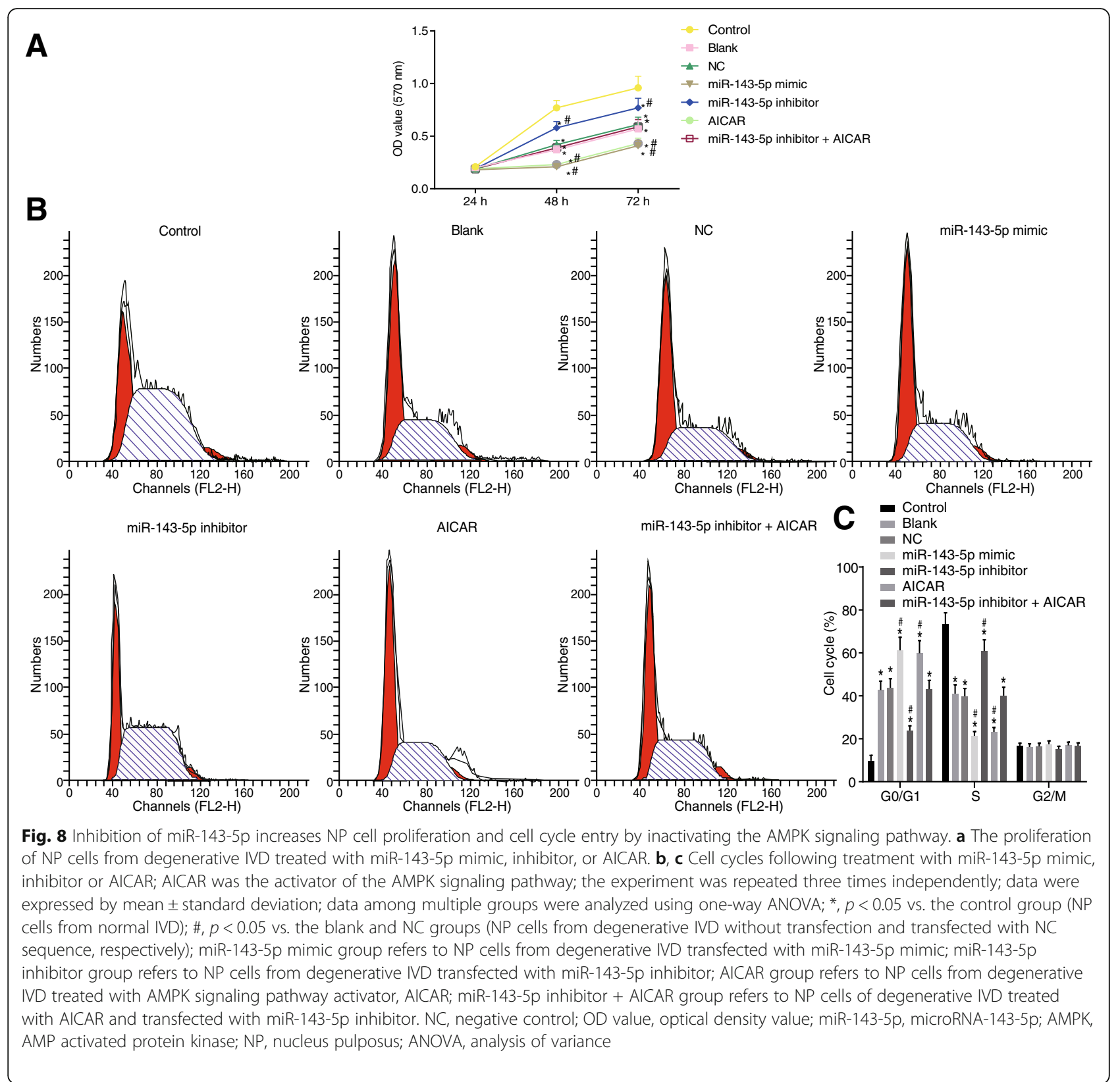

and melanogenesis in alpaca melanocyte in melanoma [31]. In addition, silencing miR-143-5p contributes to the differentiation dental pulp stem cells into odontoblasts by enhancing Runx2 expression via the OPG/RANKL signaling pathway [32]. Another important finding of this present study was that miR-143-5p suppressed NP cell proliferation and differentiation but promoted cell apoptosis and senescence in IDD. Consistently, a prior study also revealed upregulated miR-143 expression in degenerative disc tissues and restored miR-143 expression could promote IDD via negatively regulating Bcl-2 [16]. The results from the dual luciferase reporter gene assay confirmed that miR-143-5p targeted and negatively regulated eEF2. This study also found that eEF2 was expressed at a low level in degenerative IVD. eEF2, belonging to the GTP-binding translation elongation factor family, played a significant role in protein synthesis [33]. Recent evidence has indicated that the downregulation of eEF2 induced by IL- 6 can cause impairment on myogenic differentiation during muscle homeostasis [34]. Furthermore, overexpression of eEF2 contributes to the inhibition of cardiomyocyte apoptosis during myocardial ischemia reperfusion via upregulating $\mathrm{Bcl}-2$ expression [35].

In the following experiments, it was found that NP cells displayed a decreased expression ratio of $\mathrm{p}-\mathrm{mTOR} /$ 


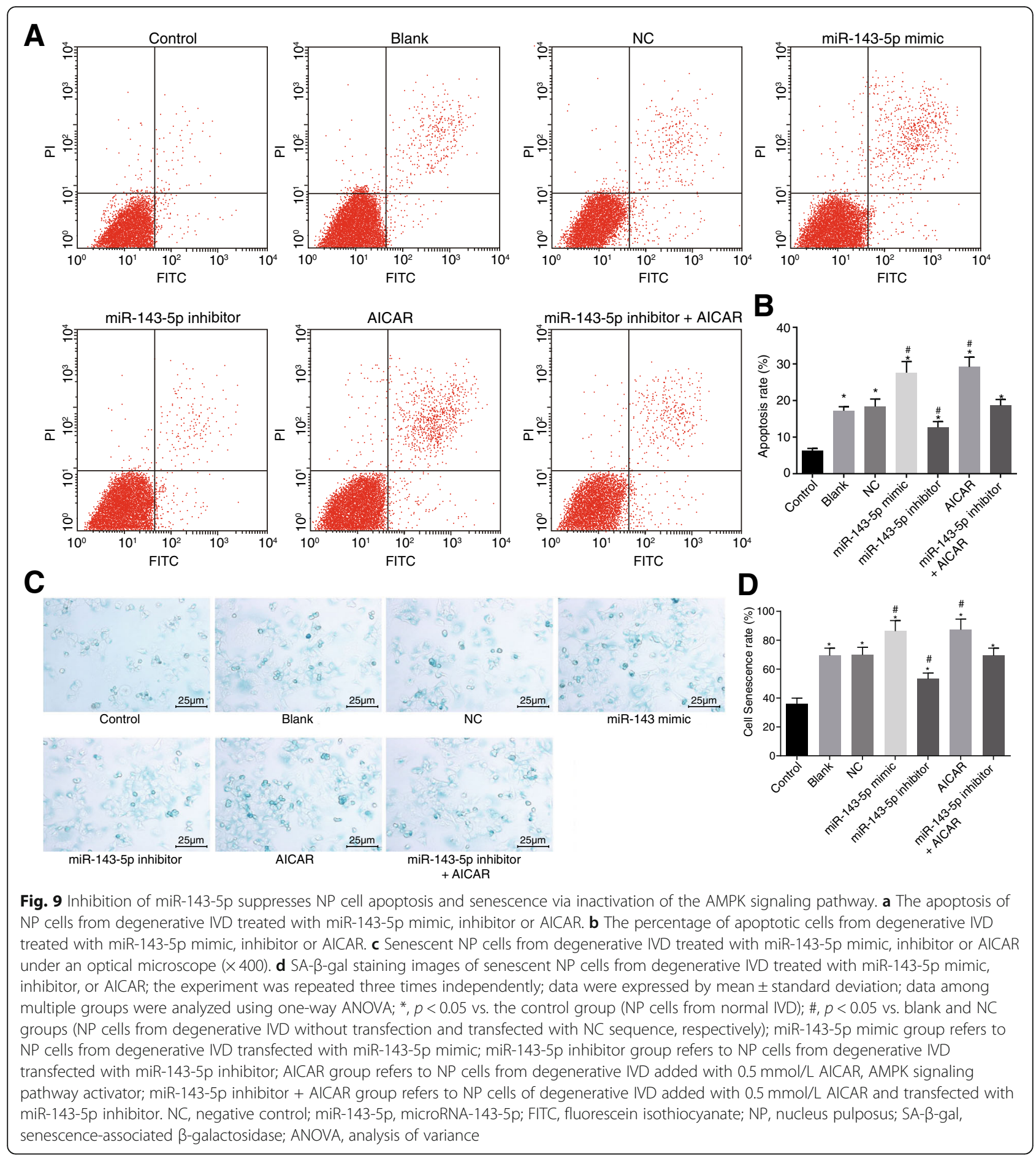

$\mathrm{t}$-mTOR and an increased expression ratio of p-AMPK/ $\mathrm{t}$-AMPK following transfection with miR-143-5p mimic. The phosphorylation of the AMPK substrates was shown to be associated with upregulation of miR-143/145 in regulating the angiotensin-converting enzyme [36]. EEF2K is the enzyme that inactivates eEF2, which is activated by AMPK $[20,21]$. It should be noted that mTOR is a protein kinase that participates in translation control and long-lasting synaptic plasticity [37], and it also played a significant role in cell senescence [38]. Furthermore, a previous study has suggested that AMPK signaling pathway is capable of inhibiting mTOR activity [39]. When the AMPK signaling pathway was activated by AICAR, NP cell proliferation and differentiation were inhibited but NP cell apoptosis and senescence were promoted. As a significant regulator of cell apoptosis [40], 
Bcl-2 has been confirmed to block apoptosis in degenerative IVD [16]. Bax is a member of Bcl-2 family [41]. Moreover, the stabilizing of the $\mathrm{Bax} / \mathrm{Bcl}-2$ ratio induces cell death and cell senescence [42]. It was also found that the cartilage differentiation-related genes COL2, ACAN, and DCN were suppressed when miR-143-5p was increased or the AMPK signaling pathway was activated. A recent study suggests that the COL2 protein level was increased when AMPK was poorly expressed [43]. It has also confirmed that DCN promotes nephron progenitor differentiation in the embryonic kidney [44]. The loss-of-function experiments further revealed that the inhibition of miR-143-5p blocked the AMPK signaling pathway and reversed the effects caused by the AMPK signaling pathway activation. Altogether, the inhibition of miR-143-5p promoted NP cell proliferation and differentiation yet restrained cell apoptosis and senescence by disrupting the AMPK signaling pathway.

\section{Conclusions}

In conclusion, this study indicated that miR-143-5p was overexpressed in IDD. Furthermore, it has been shown that miR-143-5p promotes cell senescence and inhibits cell proliferation and differentiation in NP cells. Notably, eEF2 is a target gene of miR-143-5p, and miR-143-5p activates the AMPK signaling pathway in the regulation of IDD. It was speculated that miR-143-5p is a promising therapeutic target for IDD treatment. However, further studies are still required with more detailed methods to investigate more specific mechanism of miR-143-5p in IDD.

\begin{abstract}
Abbreviations
AMPK: AMP-kinase; ANOVA: Analysis of variance; BCA: Bicinchoninic acid; BCl2: B cell lymphoma-2; BSA: Bovine serum albumin; $\mathrm{Ca} / \mathrm{CaM}$ : Calcium/ calmodulin; CT: Cycle threshold; DAB: Diaminobenzidine; DHI: Disc height index; DLR: Dual luciferase reporter; eEF2: Eukaryotic elongation factor 2; eEF2K: EEF2 kinase; ELISA: Enzyme-linked immunosorbent assay; FBS: Fetal bovine serum; GAPDH: Glyceraldehyde-3-phosphate dehydrogenase; HE: Hematoxylin-eosin; HSFs: Human hypertrophic scar fibroblasts; IDD: Intervertebral disc degeneration; IVD: Intervertebral disc; LBP: Low back pain; miRNAs: MicroRNAs; MRl: Magnetic resonance imaging; mTOR: Mammalian target of rapamycin; NC: Negative control; NP: Nucleus pulposus; OD: Optical density; PBS: Phosphate buffered saline; PI: Propidium iodide; RDHC: Rate of disc height change; RT-qPCR: Reverse transcription quantitative polymerase chain reaction; SDS-PAGE: Sodium dodecyl sulfatepolyacrylamide gel electrophoresis
\end{abstract}

\section{Acknowledgements}

We acknowledge and appreciate our colleagues for their valuable efforts and comments on this paper.

\section{Funding}

None.

\section{Availability of data and materials}

The datasets generated/analyzed during the current study are available.

\section{Authors' contributions}

QY and XPG carried out the molecular genetic studies, participated in the sequence alignment, and drafted the manuscript. QY carried out the immunoassays. YLC participated in the sequence alignment. YW participated in the design of the study and performed the statistical analysis. XPG, YLC, and YW conceived of the study and participated in its design and coordination and helped to draft the manuscript. All authors read and approved the final manuscript.

\section{Ethics approval and consent to participate}

This study was carried out in strict accordance with the recommendations in the Guide for the Care and Use of Laboratory Animals. All efforts were made to minimize suffering of the animals. The experimental procedures were approved by the Animal Ethics Committee of Taihe Hospital.

\section{Consent for publication}

Not applicable.

\section{Competing interests}

The authors declare that they have no competing interests.

\section{Publisher's Note}

Springer Nature remains neutral with regard to jurisdictional claims in published maps and institutional affiliations.

\section{Author details}

${ }^{1}$ The 3rd Ward of Department of Orthopedics Surgery, Taihe Hospital, Shiyan 442000, People's Republic of China. ${ }^{2}$ Department of Dermatology, Taihe Hospital, Shiyan 442000, People's Republic of China. ${ }^{3}$ The 2nd Ward of Department of Neurosurgery, Taihe Hospital, No. 32, Renmin South Road, Maojian District, Shiyan 442000, Hubei Province, People's Republic of China.

Received: 8 August 2018 Accepted: 11 March 2019

Published online: 15 April 2019

\section{References}

1. Wang SZ, Chang Q, Lu J, Wang C. Growth factors and platelet-rich plasma: promising biological strategies for early intervertebral disc degeneration. Int Orthop. 2015:39:927-34

2. Liu H, Pan H, Yang H, Wang J, Zhang $K$, Li X, et al. LIM mineralization protein-1 suppresses TNF-alpha induced intervertebral disc degeneration by maintaining nucleus pulposus extracellular matrix production and inhibiting matrix metalloproteinases expression. J Orthop Res. 2015;33:294-303.

3. Tisherman R, Coelho P, Phillibert D, Wang D, Dong Q, Vo N, et al. NFkappaB signaling pathway in controlling intervertebral disk cell response to inflammatory and mechanical stressors. Phys Ther. 2016;96:704-11.

4. Wang SZ, Rui YF, Tan Q, Wang C. Enhancing intervertebral disc repair and regeneration through biology: platelet-rich plasma as an alternative strategy. Arthritis Res Ther. 2013;15:220.

5. Sakai D, Mochida J, Iwashina T, Watanabe T, Suyama K, Ando K, et al. Atelocollagen for culture of human nucleus pulposus cells forming nucleus pulposus-like tissue in vitro: influence on the proliferation and proteoglycan production of HNPSV-1 cells. Biomaterials. 2006;27:346-53.

6. Jiang $L$, Zhang $X$, Zheng $X, R u A, N i X, W u$ Y, et al. Apoptosis, senescence, and autophagy in rat nucleus pulposus cells: implications for diabetic intervertebral disc degeneration. J Orthop Res. 2013;31:692-702.

7. Chen J, Xie JJ, Jin MY, Gu YT, Wu CC, Guo WJ, et al. Sirt6 overexpression suppresses senescence and apoptosis of nucleus pulposus cells by inducing autophagy in a model of intervertebral disc degeneration. Cell Death Dis. 2018;9:56.

8. Chen D, Xia D, Pan Z, Xu D, Zhou Y, Wu Y, et al. Metformin protects against apoptosis and senescence in nucleus pulposus cells and ameliorates disc degeneration in vivo. Cell Death Dis. 2016;7:e2441.

9. Watanabe T, Sakai D, Yamamoto Y, Iwashina T, Serigano K, Tamura F, et al. Human nucleus pulposus cells significantly enhanced biological properties in a coculture system with direct cell-to-cell contact with autologous mesenchymal stem cells. J Orthop Res. 2010;28:623-30.

10. Wang T, Li P, Ma X, Tian P, Han C, Zang J, et al. MicroRNA-494 inhibition protects nucleus pulposus cells from TNF-alpha-induced apoptosis by targeting JunD. Biochimie. 2015;115:1-7.

11. Liu H, Huang $X$, Liu $X$, Xiao S, Zhang $Y$, Xiang T, et al. miR-21 promotes human nucleus pulposus cell proliferation through PTEN/AKT signaling. Int J Mol Sci. 2014;15:4007-18. 
12. Kang L, Yang C, Yin H, Zhao K, Liu W, Hua W, et al. MicroRNA-15b silencing inhibits IL-1beta-induced extracellular matrix degradation by targeting SMAD3 in human nucleus pulposus cells. Biotechnol Lett. 2017;39:623-32.

13. Wang C, Wang WJ, Yan YG, Xiang YX, Zhang J, Tang ZH, et al. MicroRNAs: new players in intervertebral disc degeneration. Clin Chim Acta. 2015;450:333-41.

14. He M, Zhan M, Chen W, Xu S, Long M, Shen H, et al. MiR-143-5p deficiency triggers EMT and metastasis by targeting HIF-1alpha in gallbladder Cancer. Cell Physiol Biochem. 2017;42:2078-92.

15. Jin X, Chen X, Hu Y, Ying F, Zou R, Lin F, et al. LncRNA-TCONS_00026907 is involved in the progression and prognosis of cervical cancer through inhibiting miR-143-5p. Cancer Med. 2017;6:1409-23.

16. Zhao K, Zhang Y, Kang L, Song Y, Wang K, Li S, et al. Epigenetic silencing of miRNA-143 regulates apoptosis by targeting BCL2 in human intervertebral disc degeneration. Gene. 2017;628:259-66.

17. Mu S, Kang B, Zeng W, Sun Y, Yang F. MicroRNA-143-3p inhibits hyperplastic scar formation by targeting connective tissue growth factor CTGF/CCN2 via the Akt/mTOR pathway. Mol Cell Biochem. 2016;416:99-108.

18. Li X, Alafuzoff I, Soininen H, Winblad B, Pei JJ. Levels of mTOR and its downstream targets 4E-BP1, eEF2, and eEF2 kinase in relationships with tau in Alzheimer's disease brain. FEBS J. 2005;272:4211-20.

19. Kameshima S, Okada M, Ikeda S, Watanabe Y, Yamawaki H. Coordination of changes in expression and phosphorylation of eukaryotic elongation factor 2 (eEF2) and eEF2 kinase in hypertrophied cardiomyocytes. Biochem Biophys Rep. 2016;7:218-24.

20. Johanns M, Pyr Dit Ruys S, Houddane A, Vertommen D, Herinckx G, Hue L, et al. Direct and indirect activation of eukaryotic elongation factor 2 kinase by AMP-activated protein kinase. Cell Signal. 2017;36:212-21.

21. Pyr Dit Ruys S, Wang X, Smith EM, Herinckx G, Hussain N, Rider MH, et al. Identification of autophosphorylation sites in eukaryotic elongation factor-2 kinase. Biochem J. 2012:442:681-92.

22. Leprivier G, Remke M, Rotblat B, Dubuc A, Mateo AR, Kool M, et al. The eEF2 kinase confers resistance to nutrient deprivation by blocking translation elongation. Cell. 2013;153:1064-79.

23. Wang $X H$, Zhu L, Hong X, Wang YT, Wang F, Bao JP, et al. Resveratrol attenuated TNF-alpha-induced MMP-3 expression in human nucleus pulposus cells by activating autophagy via AMPK/SIRT1 signaling pathway. Exp Biol Med (Maywood). 2016;241:848-53.

24. Yuan W, Che W, Jiang YQ, Yuan FL, Wang HR, Zheng GL, et al. Establishment of intervertebral disc degeneration model induced by ischemic sub-endplate in rat tail. Spine J. 2015;15:1050-9.

25. Siemionow K, An H, Masuda K, Andersson G, Cs-Szabo G. The effects of age, sex, ethnicity, and spinal level on the rate of intervertebral disc degeneration: a review of 1712 intervertebral discs. Spine. 2011;36:1333-9.

26. Liu JW, Lin KH, Weber C, Bhalla S, Kelso S, Wang K, et al. An in vitro organ culture model of the murine intervertebral disc. J Vis Exp. 2017. https://doi. org/10.3791/55437.

27. Ayuk SM, Abrahamse H, Houreld NN. The role of photobiomodulation on gene expression of cell adhesion molecules in diabetic wounded fibroblasts in vitro. J Photochem Photobiol B. 2016;161:368-74.

28. Li Z, Yu X, Shen J, Chan MT, Wu WK. MicroRNA in intervertebral disc degeneration. Cell Prolif. 2015;48:278-83.

29. Zhou X, Chen L, Grad S, Alini M, Pan H, Yang D, et al. The roles and perspectives of microRNAs as biomarkers for intervertebral disc degeneration. J Tissue Eng Regen Med. 2017;11:3481-7.

30. Proctor CJ, Goljanek-Whysall K. Using computer simulation models to investigate the most promising microRNAs to improve muscle regeneration during ageing. Sci Rep. 2017;7:12314.

31. Ji K, Zhang P, Zhang J, Fan R, Liu Y, Yang S, et al. MicroRNA 143-5p regulates alpaca melanocyte migration, proliferation and melanogenesis. Exp Dermatol. 2018;27:166-71.

32. Zhan FL, Liu XY, Wang XB. The role of MicroRNA-143-5p in the differentiation of dental pulp stem cells into odontoblasts by targeting Runx2 via the OPG/RANKL signaling pathway. J Cell Biochem. 2018;119:536-46.

33. Zhu H, Yang X, Liu J, Zhou L, Zhang C, Xu L, et al. Eukaryotic elongation factor 2 kinase confers tolerance to stress conditions in cancer cells. Cell Stress Chaperones. 2015;20:217-20.

34. Pelosi M, De Rossi M, Barberi L, Musaro A. IL-6 impairs myogenic differentiation by downmodulation of p90RSK/eEF2 and mTOR/p7056K axes, without affecting AKT activity. Biomed Res Int. 2014;2014:206026.
35. Zhang C, Liu X, Zhang C, Li J, Guo W, Yan D, et al. Phosphorylated eEF2 is SUMOylated and induces cardiomyocyte apoptosis during myocardial ischemia reperfusion. J Cardiol. 2017;69:689-98.

36. Kohlstedt K, Trouvain C, Boettger T, Shi L, Fisslthaler B, Fleming I. AMPactivated protein kinase regulates endothelial cell angiotensin-converting enzyme expression via p53 and the post-transcriptional regulation of microRNA-143/145. Circ Res. 2013;112:1150-8.

37. Hoeffer CA, Klann E. mTOR signaling: at the crossroads of plasticity, memory and disease. Trends Neurosci. 2010;33:67-75.

38. Iglesias-Bartolome R, Patel V, Cotrim A, Leelahavanichkul K, Molinolo AA, Mitchell JB, et al. mTOR inhibition prevents epithelial stem cell senescence and protects from radiation-induced mucositis. Cell Stem Cell. 2012;11:401-14.

39. Amieux PS, McKnight GS. Cyclic nucleotides converge on brown adipose tissue differentiation. Sci Signal. 2010;3:pe2.

40. Souers AJ, Leverson JD, Boghaert ER, Ackler SL, Catron ND, Chen J, et al. ABT-199, a potent and selective BCL-2 inhibitor, achieves antitumor activity while sparing platelets. Nat Med. 2013;19:202-8

41. Russell LD, Chiarini-Garcia H, Korsmeyer SJ, Knudson CM. Bax-dependent spermatogonia apoptosis is required for testicular development and spermatogenesis. Biol Reprod. 2002;66:950-8.

42. Arend N, Wertheimer C, Laubichler P, Wolf A, Kampik A, Kernt M. Idebenone prevents oxidative stress, cell death and senescence of retinal pigment epithelium cells by stabilizing $\mathrm{BAX} / \mathrm{Bcl}-2$ ratio. Ophthalmologica. 2015;234:73-82.

43. Zhou Y, Liu SQ, Yu L, He B, Wu SH, Zhao Q, et al. Berberine prevents nitric oxide-induced rat chondrocyte apoptosis and cartilage degeneration in a rat osteoarthritis model via AMPK and p38 MAPK signaling. Apoptosis. 2015;20:1187-99.

44. Fetting JL, Guay JA, Karolak MJ, lozzo RV, Adams DC, Maridas DE, et al. FOXD1 promotes nephron progenitor differentiation by repressing decorin in the embryonic kidney. Development. 2014;141:17-27.

Ready to submit your research? Choose BMC and benefit from:

- fast, convenient online submission

- thorough peer review by experienced researchers in your field

- rapid publication on acceptance

- support for research data, including large and complex data types

- gold Open Access which fosters wider collaboration and increased citations

- maximum visibility for your research: over $100 \mathrm{M}$ website views per year

At $\mathrm{BMC}$, research is always in progress.

Learn more biomedcentral.com/submissions 